Original Article

\title{
Serum Bone Markers Levels and Bone Mineral Density in Familial Mediterranean Fever
}

\author{
Teoman Aydin, MD ${ }^{1)}$, Ozgur Taspinar, MD²*, Yildiz Akbal, MD ${ }^{1)}$, Celaleddin Peru, MD ${ }^{2}$, \\ Mustafa Guler, MD ${ }^{1)}$, Omer Uysal, MD ${ }^{3}$, M. Cengiz Yakicier, MD ${ }^{4}$ \\ 1) Department of Physical Therapy and Rehabilitatıon, Bezm-i Alem Vakıf Foundation University \\ School of Medicine: Istanbul, Türkiye \\ 2) Department of Internal Medicine, Bezm-i Alem Vaklf Foundatıon University School of Medicine, \\ Türkiye \\ 3) Department of Biolstatistıcs, Bezm-i Alem Vakıf Foundatıon Unıversity School of Medicıne, Türkiye \\ 4) Acıbadem University School of Medicıne, Department of Molecular Bıology and Genetıcs, Türkiye
}

\begin{abstract}
Purpose] The aim of this study was to measure bone mineral density, serum and urinary bone turnover parameters, and to evaluate the influence of demographic and genetic factors on these parameters in FMF patients. [Subjects and Methods] Twenty-seven attack-free patients who were diagnosed with FMF (in accordance with Tel Hashomer criteria) were recruited at outpatient rheumatology clinics. We investigated whether there were any differences between the FMF patients and a control group in terms of lumbar and femur bone mineral density (BMD), standard deviation scores ( $\mathrm{Z}$ scores and $\mathrm{T}$ scores) and bone markers. [Results] In terms of the median values of lumbar BMD $(p=0.21)$, lumbar $T(p=0.098)$ and $Z(p=0.109)$ scores, femoral neck BMD, femoral $T$ and $\mathrm{Z}$ scores and total femur BMD, $\mathrm{T}(\mathrm{p}=0.788)$ and $\mathrm{Z}$ scores, there were no significant differences. [Conclusion] In our study, no statistically significant differences were found between FMF patients and a control group in terms of osteoporosis. The 25-OH vitamin D was found to be significantly lower in FMF patients than in the control group. Key words: Bone mineral density, Familial mediterranean fever, Serum bone markers levels
\end{abstract}

(This article was submitted Jan. 30, 2014, and was accepted Mar. 31, 2014)

\section{INTRODUCTION}

Familial Mediterranean fever is a recurrent disease with autosomal recessive heredity which especially peritoneum, pleura and joints face with ${ }^{1}$. It is a disease specific to the Mediterranean region ${ }^{2)}$. Its frequency in the Turkish population is $1 / 3,500^{3)}$.

Although FMF changes with attacks, it does not require long-term immobilization which may cause osteoporosis. Recently, some studies have shown that subclinical inflammation continues between attacks ${ }^{4,5}$. Some pro-inflammatory cytokines such as TNF- $\alpha$, interleukins IL-1, IL-6, IL11, IL-15 and IL-17 are correlated with osteoclasts and bone resorption ${ }^{6}$, and it has been asserted that osteoporosis may occur in FMF patients. Despite conflicting results and variability in methodology, this assertion has been corroborated by few studies ${ }^{7-9)}$.

Osteocalcin, which has pro-osteoblastic or bone-building characteristics, is secreted only by osteoblasts, and it is thought to have a role in physiological metabolism ${ }^{10)}$

*Corresponding author. Ozgur Taspinar (E-mail: drozgur82@ gmail.com)

(c) The Society of Physical Therapy Science. Published by IPEC Inc.

This is an open-access article distributed under the terms of the Creative Commons Attribution Non-Commercial No Derivatives (by-ncnd) License $<$ http://creativecommons.org/licenses/by-nc-nd/3.0/> .
Osteocalcin is frequently used as an indicator of bone formation because it is produced by osteoblasts ${ }^{11}$. Deoxypyridinoline has mature collagen hydroxylysine-derived crosslinks, which are excreted in urine as a result of collagen degradation, both in free and peptide-bound forms ${ }^{12}$. It has been shown that they are sensitive bone resorption markers and also correlate well with other bone resorption markers $^{13-15}$. Significant increases in deoxypyridinoline have been shown in patients with high bone turnover states, especially in patients with osteoporosis and osteoporotic fractures, femur fractures, Paget disease, and hyperparathyroidism ${ }^{12-15)}$, vitamin D is known to be a steroid hormone required for calcium and phosphorus homeostasis and for the proper functioning of the musculoskeletal system. It has immunomodulation and pleiotropic effects. It has been shown in many animal models that vitamin D support has therapeutic effect on systemic lupus erythematosus, inflammatory bowel disease, and collagen-induced arthritis ${ }^{16-18)}$.

We investigated whether there are differences between the FMF patients and a control group in terms of lumbar and femur bone mineral density (BMD), standard deviation scores ( $\mathrm{Z}$ scores and $\mathrm{T}$ scores) and bone markers.

\section{SUBJECTS AND METHODS}

Between May 2013 and August 2013, 27 attack-free patients who were diagnosed as having FMF (in accordance with Tel Hashomer criteria) were recruited at outpatient 
rheumatology clinics ${ }^{19}$ ). Colchicine treatment $(1.5 \mathrm{mg} /$ day $)$ was being used to treat all of the patients. The control group consisting of 28 healthy individuals who were recruited for this study.

The exclusion criteria were having endocrine diseases (hyperthyroidism, hyperparathyroidism, hyperprolactinemia, hypercortisolism, hypogonadism metabolic diseases), chronic renal diseases, chronic liver diseases, malabsorption syndromes, malignant diseases, using drugs which may affect BMD (calcium, anticonvulsant drugs, heparin, warfarin, estrogen, progesterone, glucocorticoids, diuretics, antacid drugs vitamin D), having previous surgical menopause, an age younger than 18 years or receiving a osteoporosis treatment.

FMF patients determined by Hashomer criteria who were 18-65 years old, who did not fit the exclusion criteria and a control group were included in this study.

The cigarette and alcohol usage status of each of patient was investigated. FMF patients were questioned about their disease duration, attack components, and family history of FMF. Through dual-energy X-ray absorptiometry (DEXA) DPX-LUNAR, BMD measurements of the lumbar spine (anteroposterior projection of L1-L4) and left proximal femur (neck and total score) were executed. The BMD data were expressed in $\mathrm{g} / \mathrm{cm}^{2}$ and standard deviation scores $(\mathrm{Z}$ and $\mathrm{T}$ scores) were calculated. $T$ scores between -1 and -2.5 are considered to indicate osteopenia, and those equal or below -2.5 are considered to indicate osteoporosis (WHO Study Group. 1994). The number of standard deviations above or below the age- and sex-matched mean reference value is indicated by $\mathrm{Z}$ scores. The erythrocyte sedimentation rate (ESR), C-reactive protein (CRP), osteocalcin, 25-OH vitamin D, serum amyloid, deoxypyridinoline and rheumatoid factor values of the experimental and control groups were examined. Genetic analyses of the patients were also performed. The 6 genetic mutations which are often observed in Turkey are M694 V, M680I, E148Q, V726A, A744S and
$\mathrm{R} 761 \mathrm{H}$, and all of the FMF patients were examined for these mutations. We received the approval of our local ethics council for our study. Written consent to participation in this study was received from all the subjects and the study was conducted in conformity with the principles of Declaration of Helsinki.

The normality of the data distribution was tested using the Kolmogorov-Smirnov test. Continuous variables were compared using the Mann-Whitney U test. Spearman's correlation test was utilized to evaluate relationships among the parameters. The $\chi^{2}$ test was used to test differences in categorical data. Group comparisons of mutations and type of attacks were performed using the Kruskal-Wallis test. Binary regression analysis was performed in order to examine whether or not family histories of FMF were independently associated with BMD, T scores and $\mathrm{Z}$ scores. Significance was accepted for values of $\mathrm{p}<0.05$.

\section{RESULTS}

The demographic and clinical characteristics and laboratory parameters of patients and control group subjects are presented in Table 1. Among the groups, no significant difference were found in terms of age, sex, BMI, smoking habits, ESR, CRP, osteocalcin, serum amyloid, deoxypyridinoline, rheumatoid factor, urea, creatine, alkaline photophatase and CRP. Though the levels of $25-\mathrm{OH}$ vitamin D of FMF patients were found to be within low limits, the median value of the experimental group was lower than that of the control group.

The mutation characteristics of FMF patients are presented in Table 2. Patients were divided into three groups of homozygote, compound heterozygote and single heterozygote according to their mutation characteristics. We didn't detect a significant correlation among those groups using Spearman's RS test ( $\mathrm{p}>0.05)$.

No statistically significant difference was found between

Table 1. The demographic and laboratory parameters of patients with FMF and controls [number (\%)]

\begin{tabular}{|c|c|c|c|}
\hline & Patient group & Control group & $\mathrm{p}$ \\
\hline Sex $(\text { male/female) })^{\beta}$ & $10 / 17(37 \% / 63 \%)$ & $10 / 17(37 \% / 63 \%)$ & \\
\hline Age $(\text { year })^{\beta}$ & $36.2( \pm 13.3)$ & $36.78( \pm 8.89)$ & \\
\hline $\operatorname{BMI}\left(\mathrm{kg} / \mathrm{cm}^{2}\right)^{\beta}$ & $26.4( \pm 4.8)$ & $25.2( \pm 4.0)$ & \\
\hline Smokers & $4(14.8 \%)$ & $3(11.1 \%)$ & \\
\hline $\operatorname{ESR}(\mathrm{mm} / \mathrm{h})^{¥}$ & $16.7(2-65)$ & $15.2(2-33)$ & \\
\hline $\mathrm{CRP}(\mathrm{mg} / \mathrm{L})^{\ddagger}$ & $0.3(0-1.6)$ & $0.3(0-0.8)$ & \\
\hline Osteocalsin $(\mathrm{ng} / \mathrm{mL})^{¥}$ & $24.5(3.0-53.4)$ & $21.9(11-36.6)$ & \\
\hline $25-\mathrm{OH}$ vitamin $\mathrm{D}(\mathrm{ng} / \mathrm{mL})^{¥}$ & $14.7(4.2-34.7)$ & $39.0(16-110)$ & $\alpha$ \\
\hline Serum amiloid $(\mathrm{mg} / \mathrm{dL})^{¥}$ & $0.9(0.1-10.1)$ & $0.4(0.1-0.6)$ & \\
\hline Rheumotoid factor $(\mathrm{IU} / \mathrm{mL})^{\ddagger}$ & $9.8(3-46)$ & $7.7(4-12)$ & \\
\hline Deoxypyridinoline (ug g/Krea) $)^{\ddagger}$ & $50.3(16.3-314)$ & $33.6(14-48.3)$ & \\
\hline Urea (mg/dl) & $22.3(10-42)$ & $15.7(8-31)$ & \\
\hline Creatine (mg/dl) & $1.2(0.8-1.9)$ & $0.9(0.7-1.3)$ & \\
\hline $\operatorname{ALP}(\mathrm{U} / 1)$ & $92.7(52-162)$ & $82.1(45-145)$ & \\
\hline
\end{tabular}

BMI body mass index, ESR erythrocyte sedimentation rate, CRP C-reactive protein; ${ }^{\alpha} \mathrm{p}<0.05$ is significant, $\beta$ the data expressed as mean $( \pm \mathrm{SD}),{ }^{¥}$ the data expressed as median (minimum-maximum). 
the experimental and control groups in terms of median values of lumbar BMD, lumbar $\mathrm{T}$ and $\mathrm{Z}$ scores, proximal femur BMD, proximal femur $\mathrm{T}$ and $\mathrm{Z}$ scores and total femur $\mathrm{BMD}$, and total femur $\mathrm{T}$ and $\mathrm{Z}$ scores (Table 3 ).

All of our patients were taking $1.5 \mathrm{mg} /$ day colchicine. Considering the colchicine usage duration of patients and

Table 2. Mutation characteristics of patients with FMF [number (\%)]

\begin{tabular}{lc}
\hline No mutation & $3(11 \%)$ \\
Mutations & $24(89 \%)$ \\
Homozygote & $7(25 \%)$ \\
M694V/M694V & $4(14 \%)$ \\
M680I/M680I & $2(7 \%)$ \\
V726A / V726A & $2(7 \%)$ \\
Compound heterozygote & $9(33 \%)$ \\
M694V / E148Q & $2(7 \%)$ \\
M680I / E148Q & $1(3 \%)$ \\
M680I / M694I 2 (4.5\%) & $1(3 \%)$ \\
E148Q / V726A & $1(3 \%)$ \\
E148Q / A744S & $1(3 \%)$ \\
M680I / V726A & $1(3 \%)$ \\
E148Q / R761H & $1(3 \%)$ \\
M694V / V726A & $1(3 \%)$ \\
Heterozygote & $7(25 \%)$ \\
M694V & $2(7 \%)$ \\
V726A & $2(7 \%)$ \\
M680I & $1(3 \%)$ \\
E148Q & $1(3 \%)$ \\
R761H & $1(3 \%)$ \\
\hline
\end{tabular}

other variables, the serum amyloid level and BMI values of patients who had used colchicine for 20 or more years was found to be significantly higher $(\mathrm{p}=0.038 ; \mathrm{p}=0.018$ ) (Table $4)$. There were no relationships among lumbar BMD, lumbar $\mathrm{T}$ and $\mathrm{Z}$ scores, proximal femur BMD, proximal femur $\mathrm{T}$ and $\mathrm{Z}$ scores and total femur BMD, total femur $\mathrm{T}$ and $\mathrm{Z}$ scores, other parameters and colchicine usage according to the Spearman's RS test $(\mathrm{p}>0.05)$.

\section{DISCUSSION}

In our present study, we didn't find any difference between the FMF patients and control groups in terms of lumbar BMD, proximal femur BMD, and total femur BMD which we used us as bone mineral density markers. No differences were found between patients' inter-peer and interadult total femur $\mathrm{T}$ and $\mathrm{Z}$ scores, lumbar $\mathrm{T}$ and $\mathrm{Z}$ scores, and proximal femur $\mathrm{T}$ and $\mathrm{Z}$ scores. No differences were found between the groups in terms of ESR, CRP, bone formation marker osteocalcin, bone resorption marker deoxypyridinoline, serum amyloid, rheumatoid factor, urea, creatine, alkaline phosphatase, hemoglobin, and TSH. But the FMF patient group's level of 25-OH vitamin D was found to be significantly low.

Circulating levels of vitamin D have been shown to improve several inflammatory conditions including rheumatoid arthritis, systemic lupus erythematosus and Behcet's disease $^{20-22)}$. Kisacik et al. carried out a study of 26 FMF patients and a control group consisting of 34 individuals, and found serum 25-OH vitamin D levels to be low $(p<0.001)^{23)}$. This result is in agreement with others found in the literature.

In a study of 28 FMF patients and control group consisting of 30 people, Yildırım et al. compared the BMD, T score

Table 3. BMD, $\mathrm{Z}$ and $\mathrm{T}$ scores of patient and control groups (mean $( \pm \mathrm{SD})$ )

\begin{tabular}{lccc}
\hline & FMF patients $(\mathrm{n}=27)$ & Controls $(\mathrm{n}=27) \mathrm{p} \mathrm{value}^{\alpha}$ \\
\hline Lumbar (L1-4) BMD & $1.13 \pm 0.13$ & $1.19 \pm 0.21$ & $\mathrm{p}>0.05$ \\
Lumbar (L1-4) T SCORE & $-0.30 \pm 1.01$ & $0.34 \pm 1.67$ & $\mathrm{p}>0.05$ \\
Lumbar (L1-4) Z SCORE & $-0.17 \pm 0.99$ & $0.42 \pm 1.60$ & $\mathrm{p}>0.05$ \\
Femoral neck BMD & $1.01 \pm 0.16$ & $0.95 \pm 0.15$ & $\mathrm{p}>0.05$ \\
Femoral neck T SCORE & $-0.13 \pm 1.03$ & $-0.33 \pm 1.25$ & $\mathrm{p}>0.05$ \\
Femoral neck Z SCORE & $0.14 \pm 1.07$ & $-0.15 \pm 1.22$ & $\mathrm{p}>0.05$ \\
Total femur BMD & $1.03 \pm 0.16$ & $0.98 \pm 0.21$ & $\mathrm{p}>0.05$ \\
Total femur T SCORE & $-0.09 \pm 1.17$ & $0.02 \pm 1.79$ & $\mathrm{p}>0.05$ \\
Total femur Z SCORE & $0.10 \pm 1.20$ & $0.15 \pm 1.79$ & $\mathrm{p}>0.05$ \\
\hline
\end{tabular}

Table 4. Colchicine use and mean amyloid

\begin{tabular}{lcccc}
\hline Colchicine use (year) & $\mathrm{n}$ (number) & $\%$ & Amyloid $(\mathrm{mg} / \mathrm{dL})$ & $\mathrm{BMI}\left(\mathrm{kg} / \mathrm{cm}^{2}\right)$ \\
\hline None & 1 & 3.7 & 0.46 & 26.06 \\
1-5 year & 8 & 29.6 & 0.34 & 23.20 \\
6-10 year & 5 & 18.5 & 0.56 & 26.45 \\
$11-15$ year & 4 & 14.8 & 0.46 & 25.79 \\
$16-20$ year & 9 & 33.3 & 1.96 & 29.55 \\
\hline
\end{tabular}


and $\mathrm{Z}$ scores of the lumbar, femur total and femur neck regions. The FMF patient group's values were found to be significantly lower during analyses ${ }^{7}$.

Berkdemir Siverekli et al. made dual energy X-ray absorptiometry measurements of 44 FMF patients and a control group consisting of 36 people, and compared the BMD, $\mathrm{T}$ score and $\mathrm{Z}$ scores of the lumbar, femur total and femur neck regions. No significant differences were found between the groups in their analysis ${ }^{24)}$.

Yüksel et al. investigated BMD and Z scores in the lumbar and proximal femur regions of $31 \mathrm{FMF}$ patients and a control group consisting of 18 individuals, and found the values in the lumbar and proximal femur regions to be significantly lower than those of the control group ${ }^{8)}$.

In their study of patients with rheumatoid arthritis, Matuszewska et al. found that serum osteocalcin and procollagen type-I C-terminal peptide levels were low. Franck et al. ${ }^{25)}$ found that the serum osteoprotegerin levels of AS patients were statistically significantly lower than those of the control group, in both men and premenopausal and postmenopausal women. Kim et al. ${ }^{26)}$ studied 60 AS patients (51 men and 9 premenopausal women) and found the serum levels of OPG in AS patients were not different from those of the control group, while the serum levels of RANKL was found to be higher in the AS group than control in the group. In our study, deoxypyridinoline, osteocalcin, and alkaline phosphate were found to be normal.

In this study, we grouped the patients in terms of detected homozygote, compound heterozygote and single heterozygote mutations in order to examine the possible effects of these mutations on bone loss. We didn't find any statistically significant difference between the three groups in terms of BMD, and $\mathrm{Z}$ and $\mathrm{T}$ scores. This result indicates that the mutation type in FMF does not have an effect on osteoporosis, and corresponds with the other results published in literature ${ }^{5,8)}$.

In previous study, a significant relationship was found between the $m 694 \mathrm{v}$ gene and amyloidosis ${ }^{8}$. The serum amyloid level of the group having the homozygote mutation was found to be high. This result also corresponds with the other results published in literature.

Colchicine treatment prevents osteoporosis. All of our patients were taking colchicine so we could not make comparisons with patients who had not been receiving colchicine treatment. Such an investigation would require not giving colchicine to FMF patients, but that is not ethically acceptable ${ }^{5,9)}$. Considering the colchicine usage durations of patients and other variables, the serum amyloid level and BMI values were found to be significantly higher in patients who had used colchicine for 20 years or more. This is related to their age and the duration of the disease.

In chronic FMF patients, osteoporosis is expected due to inflammation. In our study, the mean age of the FMF patients was 36 . This age group constitutes a relatively young adult group, and their dexa values may have been found to be low due to that.

As mentioned above, a net consensus on the osteoporosis condition of FMF patients cannot be achieved by reference to the literature. Further randomized controlled studies should be performed on more patients to illuminate their condition.

\section{REFERENCES}

1) Ben-Chetrit E, Levy M: Familial Mediterranean fever. Lancet, 1998, 351: 659-664. [Medline] [CrossRef]

2) Ben-Chetrit E, Touitou I: Familial mediterranean Fever in the world. Arthritis Rheum, 2009, 61: 1447-1453. [Medline] [CrossRef]

3) Tunca M, Akar S, Onen F, et al. Turkish FMF Study Group: Familial Mediterranean fever (FMF) in Turkey: results of a nationwide multicenter study. Medicine (Baltimore), 2005, 84: 1-11. [Medline] [CrossRef]

4) Tunca M, Kirkali G, Soytürk M, et al.: Acute phase response and evolution of familial Mediterranean fever. Lancet, 1999, 353: 1415. [Medline] [CrossRef]

5) Duzova A, Ozaltin F, Ozon A, et al.: Bone mineral density in children with familial Mediterranean fever. Clin Rheumatol, 2004, 23: 230-234. [Medline] [CrossRef]

6) Mundy GR: Osteoporosis and inflammation. Nutr Rev, 2007, 65: S147S151. [Medline] [CrossRef]

7) Yildirim K, Karatay S, Cetinkaya R, et al.: Bone mineral density in patients with familial Mediterranean fever. Rheumatol Int, 2010, 30: $305-$ 3087.

8) Yuksel S, Samli H, Colbay M, et al.: Increased serum osteoprotegerin levels associated with decreased bone mineral density in familial Mediterranean fever. Tohoku J Exp Med, 2009, 217: 321-327. [Medline] [CrossRef]

9) Suyani E, Ozturk MA, Deger SM, et al.: Decreased bone mineral density in adult familial Mediterranean fever patients: a pilot study. Clin Rheumatol, 2008, 27: 1171-1175. [Medline] [CrossRef]

10) Lee NK, Sowa H, Hinoi E, et al.: Endocrine regulation of energy metabolism by the skeleton. Cell, 2007, 130: 456-469. [Medline] [CrossRef]

11) Bharadwaj S, Naidu AG, Betageri GV, et al.: Milk ribonuclease-enriched lactoferrin induces positive effects on bone turnover markers in postmenopausal women. Osteoporos Int, 2009, 20: 1603-1611. [Medline] [CrossRef]

12) McLaren AM, Hordon LD, Bird HA, et al.: Urinary excretion of pyridinium crosslinks of collagen in patients with osteoporosis and the effects of bone fracture. Ann Rheum Dis, 1992, 51: 648-651. [Medline] [CrossRef]

13) Rosen HN, Dresner-Pollak R, Moses AC, et al.: Specificity of urinary excretion of cross-linked N-telopeptides of type I collagen as a marker of bone turnover. Calcif Tissue Int, 1994, 54: 26-29. [Medline] [CrossRef]

14) Delmas PD, Schlemmer A, Gineyts E, et al.: Urinary excretion of pyridinoline crosslinks correlates with bone turnover measured on iliac crest biopsy in patients with vertebral osteoporosis. J Bone Miner Res, 1991, 6: 639-644. [Medline] [CrossRef]

15) Robins SP, Black D, Paterson CR, et al.: Evaluation of urinary hydroxypyridinium crosslink measurements as resorption markers in metabolic bone diseases. Eur J Clin Invest, 1991, 21: 310-315. [Medline] [CrossRef]

16) Lemire JM, Ince A, Takashima M: 1,25-Dihydroxyvitamin $D 3$ attenuates the expression of experimental murine lupus of MRL/1 mice. Autoimmunity, 1992, 12: 143-148. [Medline] [CrossRef]

17) Cantorna MT, Munsick C, Bemiss C, et al.: 1,25-Dihydroxycholecalciferol prevents and ameliorates symptoms of experimental murine inflammatory bowel disease. J Nutr, 2000, 130: 2648-2652. [Medline]

18) Cantorna MT, Hayes CE, DeLuca HF: 1,25-Dihydroxycholecalciferol inhibits the progression of arthritis in murine models of human arthritis. J Nutr, 1998, 128: 68-72. [Medline]

19) Livneh A, Langevitz $P$, Zemer $D$, et al.: Criteria for the diagnosis of familial Mediterranean fever. Arthritis Rheum, 1997, 40: 1879-1885. [Medline] [CrossRef]

20) Oelzner P, Müller A, Deschner F, et al: Relationship between disease activity and serum levels of vitamin D metabolites and PTH in rheumatoid arthritis. Calcif Tissue Int, 1998, 62: 193-198. [Medline] [CrossRef]

21) Szodoray $P$, Tarr $T$, Bazso A, et al.: The immunopathological role of vitamin D in patients with SLE: data from a single centre registry in Hungary. Scand J Rheumatol, 2011, 40: 122-126. [Medline]

22) Hamzaoui K, Ben Dhifallah I, Karray E, et al.: Vitamin D modulates peripheral immunity in patients with Behçet's disease. Clin Exp Rheumatol, 2010, 28: S50-S57. [Medline]

23) Kisacik B, Kaya SU, Pehlivan Y, et al.: Decreased vitamin D levels in patients with familial mediterranean fever. Rheumatol Int, 2013, 33: 1355 1357. [Medline] [CrossRef]

24) Berkdemir Siverekli N, Sahin O, Senel S, et al.: Bone mineral density in familial Mediterranean fever. Rheumatol Int, 2012, 32: 2453-2457. [Medline] [CrossRef] 
25) Franck H, Meurer T, Hofbauer LC: Evaluation of bone mineral density, hormones, biochemical markers of bone metabolism, and osteoprotegerin serum levels in patients with ankylosing spondylitis. J Rheumatol, 2004, 31: 2236-2241. [Medline]
26) Kim HR, Lee SH, Kim HY: Elevated serum levels of soluble receptor activator of nuclear factors-kappaB ligand (sRANKL) and reduced bone mineral density in patients with ankylosing spondylitis (AS). Rheumatology (Oxford), 2006, 45: 1197-1200. [Medline] [CrossRef] 